\title{
Association of Diabetic Retinopathy in relation with HbA1c Levels
}

\author{
Authors
}

\section{Dr Srinivas Phani Nakkella*, Dr Jayashree S Shah, Dr Sharath Kumar D Shah, Dr Sunil Kumar Kadubandi, Dr Shelly Sharma}

Sri Siddhartha Medical College Hospital \& Research Centre, Agalakote, Tumkur.

*Corresponding Author

Dr Srinivas Phani Nakkella

Junior Resident, Department Of Ophthalmology, SSMC, Tumkur

\section{Abstract}

Purpose: To assess the association and correlation of Diabetic Retinopathy with HbAlclevels. Materials and Methods: 100 patients of type 2 diabetics were examined in the present study.

Results: Out of 100 patients in the study, the mean age of Diabetes Mellitus is 15.99 years +5.68 years. The mean of HbAlc in the study population was $9.25+1.59$. The range of HbAlc was $8.6 \%$ to $10.5 \%$.

Conclusion: The severity of Diabetic Retinopathy is increased with age and duration of Diabetes Mellitus. The HbAlc levels showed an increase, with the severity of Diabetic Retinopathy. The high HbAlc levels showed the presence of CSME (Clinically Significant Macular Edema).

Keywords: Diabetic retinopathy, NPDR, PDR, HbAlc.

\section{Introduction}

Diabetes is the group of metabolic diseases characterized by hyperglycemia resulting from a defect in insulin secretion, insulin action, or both. It is the most critical disease which can affect nearly every organ system in the body. ${ }^{1}$

Diabetes is the most common metabolic abnormality in humans. ${ }^{2}$ Type 2 diabetes is the most prevalent form of diabetes constituting nearly $90 \%$ of the diabetic population. ${ }^{3}$ India with the most significant number of diabetic subjects earned the title Diabetes capital of the world.The presence of diabetic retinopathy indicates microcirculatory dysfunction in other organ systems. ${ }^{4}$

Diabetic retinopathy: It is the chronic progressive sight-threatening disease of retinal microvasculature associated with prolonged hyperglycemia. Diabetic retinopathy is the leading cause of preventable blindness in the United States in people 18 to 65 years of age. ${ }^{5}$ It used to be 17th cause of blindness but now ascended to 6 positions with an estimated 5.8 million affected diabetic retinopathy patients. ${ }^{6}$

HbA1c: $\mathrm{N}$ terminal valine residue of erythrocyte hemoglobin becomes glycosylated irreversibly with proportion to circulating glucose concentrations in the blood, and the resultant product is referred to as $\mathrm{HbA1c}{ }^{7}$

As the life span of glycosylated Hemoglobin is 120 days, unlike FBS and PPBS, it gives us a long term glycemic values. ${ }^{8}$ Henceforth to diagnose pre-diabetes and diabetes, American Diabetic Association is recommending $\mathrm{HbA} 1 \mathrm{c}$ is to be considered. The present clinical study was performed to investigate the relationship between glycosylated hemoglobin (HbA1c) levels and the severity of diabetic retinopathy. 


\section{Materials and Method}

A cross-sectional study was conducted in 100 patients already diagnosed with type 2 diabetes attending OPD at a tertiary care centre, Tumkur. Patients with Diabetic retinopathy changes were included in the study and their HbA1c levels were documented. Patients with other systemic diseases that could manifest as retinal pathology and with hazy ocular media were excluded. After taking informed consent, all patients were examined according to a predesigned proforma. Relevant history regarding diabetes concerningthe age of onset, duration, nature, and effect of treatment received was taken.

A general physical examination was performed, followed by a complete ophthalmic examination. A detailed fundus evaluation was performed using direct ophthalmoscopy, indirect ophthalmoscopy, along with slit-lamp biomicroscopy with a +90D lens.

The retinopathies were observed and documented by the modified ETDRS classification as follows:

1. MildNPDR.

2. Moderate NPDR.

3. Severe NPDR.

4. Early PDR.

5. High-Risk PDR.

All patients were subjected to fundus photography.

The data obtained from the patients are presented in tabulated forms. Mean, median, and standard deviation are calculated. Data entry was done using an Excel spreadsheet, and descriptive statistics including frequencies of various functional outcomes, are computed using Epi.info.

\section{Results}

Table 1 shows the demographic data of 100 patients included in our study. The mean age of participants in this study was $63.79 \pm 8.47$, and out of the 100 participants, M:F ratio was 1.27:1. The mean ag eof 100 patients at diagnosis was 49 \pm 5.95 and mean duration of the diabetes was $15.99 \pm 5.68$. The mean of Glycosylated hemoglobin $(\mathrm{HbA} 1 \mathrm{c})$ in the study population was $9.25 \pm 1.59$.

Among 100 participants, there were 56 Males and 44 Females in our study group, revealing a male predominance in our recruited studypopulation. The male to female ratio was $1.27: 1$, as shown in table 2 .

Prevalence of Retinopathy

Our study constituted 17\% mild NPDR, 18\% moderate NPDR, $48 \%$ severe NPDR, $13 \%$ PDR and 4\% high risk PDR. Out of 100 retinopathy patients studied severe and very severe NPDR accounted fornearly half the patients while the other half consisted of early PDR, mild and moderate NPDR, the latter beinghigher than the former as shown in graph 1.

Correlation of $\mathrm{HbAlc}$ with the severity of Retinopathy

Table 3 reveals that there were $85 \%$ of mild NPDR cases, $62 \%$ of moderate NPDR cases, and $14 \%$ of PDR cases in $6.5 \%-8.5 \%$ range of $\mathrm{HbA1c}$. Whereas in HbA1c range of $8.6 \%$ $10.5 \%$, mild and moderate NPDR cases reduced to $15 \%$ and $29 \%$ respectively, and severe NPDR cases increased to 53\%. Early PDR cases raised from $38 \%$ in $6.5 \%-8.5 \%$ range of $\mathrm{HbA} 1 \mathrm{c}$ to $46 \%$ in $8.6 \%-10.5 \%$. And high-risk PDR casesraised from $25 \%$ to $50 \%$ when $\mathrm{HbA} 1 \mathrm{c}$ raises from $6.5 \%$ - $8.5 \%$ to $8.6 \%-10.5 \%$. This revealed an increasing trend of the severity of retinopathy with raise in $\mathrm{HbA1c}$ levels.

Mean and Standard Deviation of HbA1c in retinopathy

Table 4 shows the means of HbAlc in each level of severity of diabetic retinopathy. The mean of HbA1c in mild NPDR was $7.62+0.49$. In moderate NPDR, it was $8.66+1.48$. In severe NPDR $10.06+1.42$.In Early PDR $9.0+1.32$ and in High risk PDR $9.48+2.09$. Therefore, as the severity of retinopathy increased, the mean HbA1c for that level of severity also increased. The standard deviation (S.D) ineach group is small. 
Table 1 Demographic data of patients

\begin{tabular}{|l|c|}
\hline Parameters & Observation \\
\hline Total participants included & 100 \\
\hline M: F & $1.27: 1$ \\
\hline Mean age (years) & $63.79 \pm 8.47$ \\
\hline Mean age at diagnosis (years) & $49 \pm 5.95$ \\
\hline Mean duration of diabetes (years) & $15.99 \pm 5.68$ \\
\hline Mean HbA1c(\%) & $9.25 \pm 1.59$ \\
\hline
\end{tabular}

Table 2 Gender Distribution

\begin{tabular}{|l|c|c|}
\hline Gender & Total & M:F \\
\hline Male & 56 & $1.27: 1$ \\
\hline Female & 44 & \\
\hline Total & 100 & \\
\hline
\end{tabular}

Table 3 Correlation of HbA1c with the severity of Retinopathy

\begin{tabular}{|l|c|c|c|c|c|}
\hline \multirow{2}{*}{$\begin{array}{l}\text { HbA1c } \\
(\boldsymbol{\%})\end{array}$} & \multicolumn{5}{|c|}{ Severity of retinopathy } \\
\cline { 2 - 6 } & Mild NPDR & $\begin{array}{c}\text { Moderate } \\
\text { NPDR }\end{array}$ & $\begin{array}{c}\text { Severe } \\
\text { NPDR }\end{array}$ & Early PDR & $\begin{array}{c}\text { High } \\
\text { Risk PDR }\end{array}$ \\
\hline $6.5-8.5$ & $13(93 \%)$ & $12(55 \%)$ & $6(13 \%)$ & $2(15 \%)$ & $1(25 \%)$ \\
\hline $8.6-10.5$ & $1(7 \%)$ & $7(32 \%)$ & $26(55 \%)$ & $7(54 \%)$ & $2(50 \%)$ \\
\hline $10.6-12.5$ & 0 & 2 & 13 & 4 & 1 \\
\hline $12.6-14.5$ & 0 & 1 & 2 & 0 & 0 \\
\hline Total & 14 & 22 & 47 & 13 & 4 \\
\hline
\end{tabular}

Table 4 Mean and Standard Deviation of HbA1c in retinopathy

\begin{tabular}{|l|c|c|}
\hline \multirow{2}{*}{ Retinopathy } & \multicolumn{2}{|c|}{ HbA1c } \\
\cline { 2 - 3 } & Mean & SD \\
\hline Mild NPDR & 7.62 & 0.49 \\
\hline Moderate NPDR & 8.66 & 1.48 \\
\hline Severe NPDR & 10.06 & 1.42 \\
\hline Early PDR & 9.00 & 1.32 \\
\hline High-risk PDR & 9.48 & 2.09 \\
\hline
\end{tabular}

Graph 1 Prevalence of Retinopathy

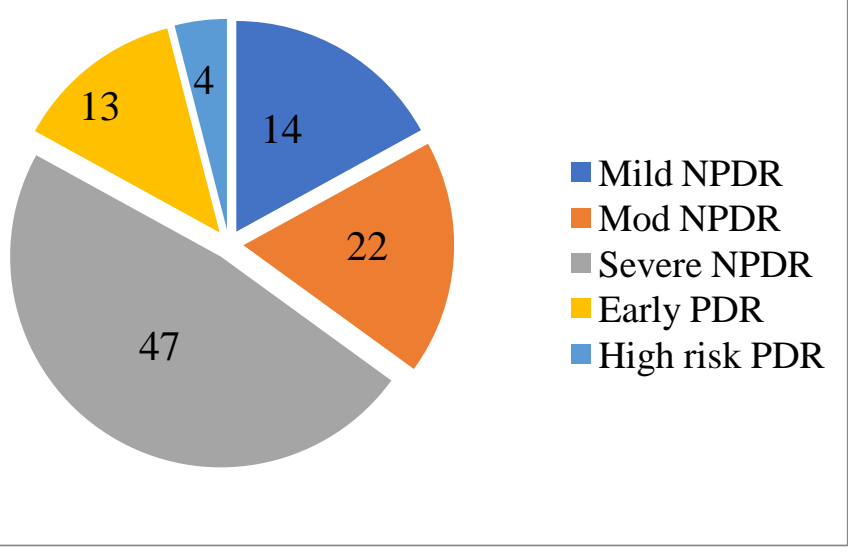

\section{Discussion}

The present study was conducted as a descriptive observational study to determine the correlation of HbA1c levels with diabetic retinopathy.
Prevalence of retinopathy:

The present study included 100 cases of retinopathy, which constituted $17 \%$ mild NPDR, $18 \%$ moderate NPDR, $48 \%$ severe NPDR, $13 \%$ 
PDR, and 4\% high-risk PDR. Regardless of the severity of retinopathy, $23 \%$ of cases had CSME.

A south Indian study by Mohan R. reported an overall prevalence of NPDR in $6 \%$, while $4 \%$ had macular edema, and $4 \%$ had PDR. ${ }^{9}$ A Chennai study revealed the prevalence of DR was $34.1 \%$. Theprevalence included $30.8 \%$ with NPDR, $3.4 \%$ with PDR and $6.4 \%$ had DME. ${ }^{10}$

The differences in the findings could be attributed to variable population Characteristics as the age ofonset, diabetic duration, treatment and adherence.

HbA1c and severity of retinopathy:

Our study revealed that mean values of HbA1c in non-proliferative types of diabetic retinopathy havean indisputable difference. The standard deviation of each level being considerably small, made the differencemore relevant. When the HbA1C values were compared in the groups with increasing severity of retinopathy, risinglevels of HbA1C were noted showing a significant correlation. Therefore, it was pointed out that poor glycemiccontrol led to the worsening of the retinopathy.

The Diabetes Control and Complications Trial (DCCT) and the U.K. Prospective Diabetes study (UKPDS) were the two randomized clinical trials that conclusively showed the efficacy of glycemic control inpreventingthe severity of diabetic retinopathy. These studies mentioned that glycemic control was protective for all levels ofretinopathy. ${ }^{11}$

HbAlc with CSME:

Comparison of the mean of HbAlc in patients with and without CSME revealed a statistically significant association of CSME with HbA1c levels. High glycosylated hemoglobin (HbAlc) level is a well-knownrisk factor for diabetic macular edema. Also, the DCCT had demonstrated that intensive treatment tomaintain blood glucose levels at a normal range reduced the risk of clinically significant macular edema at therate of $23 \% .^{12,13}$

A recent study in this regard has shown that mean HbA1c in patients with persistent unilateral
CSME was $8.6 \%$ and that in bilateral CSME was $9.1 \%$. The same study also revealed that people with type 2 diabetes with persistent CSME havehigher $\mathrm{HbA1c}$ values at the time of their disease than patients with resolved CSME.

\section{Conclusion}

The value of glycosylated hemoglobin (HbA1c) showed an increasing trend as the severity of diabeticretinopathy increases. The poor metabolic control, as demonstrated by high $\mathrm{HbAlc}$, is significantly associated with the severity of retinopathy and the presence of CSME. From the analysis of our study, we recommend maintaining HbA1c levels below 7.5\%, which reduces the risk of progression of diabetic retinopathy.

Duration of diabetes and high HbA1c levels are found to be the significant predictors of diabetic retinopathy in typeII diabetes mellitus.

\section{Acknowledgment: Nil \\ Financial support: Nil}

\section{References}

1. Pradeepa R, Deepa R, Mohan V Epidemiology of diabetes in India-current perspective and future projections. J Indian Med Assoc. 2002 Mar; 100(3):144-8.

2. Kalantzis.G, Angelou.M, Rebelakou E.F, Diabetic retinopathy: A historical assessment, Hormones 2006, 5(1):71 -74.

3. Report on the conference on 'VISION 2020 Planning for Eastern Mediterranean Region 1 Dec. 2003, Cairo, Egypt. (WHO/EMR/PBL/03.1).

4. Fauci AS,Braunwald E,KasperDL, Mauser DL,Longo DL, Jameson JL, et al.,editors,Harrison's Principles of internal medicine, diabetic retinopathy, 19th ed. New York:McGraw Hill;2422-2424.

5. Diabetic Retinopathy Eye Screenings https://www.assuredwomenswellness.com/ diabetic-retinopathy-eye-screenings.

6. Sacks DB, Bruns DE, Goldstein DE, Maclaren NK, McDonald JM, Parrott M. 
Guidelines and recommendations for laboratory analysis in the diagnosis and management of diabetes mellitus. Clin Chem. 2002;48:436-472.

7. All Jawa, Juanita KG, Vvian A, Fonesca (2004) Diabetic Nephropathy and Retinopathy Sunil Gupta, Ajay Ambade. Prevalence of diabetic retinopathy and influencing factors amongst type 2 diabetics from central India. International J. of diabetes in developing countries.2004:24:75-78

8. Wild S, Roglic G, Green A. Global prevalence of diabetes, estimates for the year 2000, and projections for 2030. Diabetes Care 2004;27:1047-53.

9. Rema M, Ponnaiya M, Mohan V. Prevalence of retinopathy in non-insulin dependent diabetes mellitus at a diabetes centre in southern India. Diabetes Res ClinPract 1996; 34: 29-36.

10. Dandona L, Dandona R, Naduvilath TJ, McCarty CA, Rao GN. Population-based assessment of diabetic retinopathy in an urban population in southern India. Br J Ophthal 1999; 83: 937-40.

11. The Diabetes Control and Complication Trial Research Group. The effectof intensivetreatment of diabetes on the development and progression of long term complications in insulin-dependent diabetes mellitus. N.Engl J Med 1993:329:977-86.

12. Do DV, Shah SM, Sung JU, Haller JA, Nguyen QD. Persistent diabetic macular edema is associated with elevated hemoglobin Alc.Am J Ophthalmol. 2005 Apr:139(4):620-3.
13. Stratton I.M et.al. Association of glycemia with macrovascular and microvascular complications of type 2 diabetes (UKPDS 35): Prospective observational study. BMJ 2000, 321:405-412. 